\title{
Presentación
}

\section{Qhapaq Ñan I, Taller Internacional en torno al Sistema Vial Inkaico (Segunda Parte)}

El número 2 del volumen 22 del Boletín del Museo Chileno de Arte Precolombino, presenta los nueve artículos finales seleccionados y evaluados correspondientes a las actas del Qhapaq Ñan I, Taller Internacional en torno al Sistema Vial Inkaico. Este segundo grupo de trabajos testimonia la variedad de las propuestas expuestas en la reunión desarollada a fines de marzo de 2015 en San Pedro de Atacama, Chile. Sumados a los ocho artículos precedentes del número 1, completa un total de 18 escritos -considerando entre ellos el homenaje dedicado al Dr. J. Roberto Bárcena-, que dan cuenta de un quehacer investigativo inédito sobre el repertorio vial del Inka, efectuado exclusivamente por investigadores sudamericanos de Perú, Bolivia, Argentina y Chile. ${ }^{1}$

Se encuentran en este número las propuestas metodológicas de Alfredo Bar, en relación a la sectorización y nomenclatura del Qhapaq Ñan como una herramienta de estandarización del registro caminero de campo. Luego, Joseph Bernabé resume las características de la red vial inka en la Pampa de Lampas, al sur del Callejón de Huaylas, en el Departamento de Ancash, detallando un camino formalizado de $28 \mathrm{~m}$ de ancho, los asentamientos implementados y el papel jugado por el camino en las interacciones sociopolíticas y económicas, como también en el ámbito ceremonial. A continuación, Guido Casaverde plantea la importancia del reconocimiento de una serie de aspectos viales y de la geografía que posibilitan discutir sobre la movilidad y la cronología relativa de los caminos, tomando como ejemplo el derrotero del Pariacaca, en el distrito de Tanta, Departamento de Lima. Estos tres primeros trabajos se han generado en el marco del Proyecto Qhapaq Ñan del Ministerio de Cultura de Perú, y prueban el compromiso efectivo del Estado Peruano con un bien patrimonial único, situación que hasta el momento no es replicada en el resto de los otros paises sudamericanos con evidencias viales inkaicas.

En un territorio argentino emblemático para los estudios prehispánicos del Noreste Argentino, como es la Quebrada de Humahuaca, Pablo Ochoa y Clarisa Otero exponen las características y la variabilidad arquitectónica del sistema vial inkaico en el sector central de dicha quebrada, que expresa para los autores las conexiones del camino con determinados sitios, pero que también integra la gravitación simbólica del paisaje en la organización del espacio.

Desde Bolivia, Walter Sánchez reune antecedentes documentales para reconstruir la entrada de Francisco de Hinojosa en el siglo xvı a la "Montaña de los Moxos", en Cochabamba.

1 El Dr. Eduardo Almeida de Ecuador, por un compromiso institucional, publicó su ponencia del taller en una revista del ese país, mientras que los colegas de Colombia, no enviaron las rectificaciones a su artículo original. 
Estudia las posibles rutas de ingreso de los españoles en época colonial, buscando definir la existencia de las poblaciones locales que habitaban dicha región y precisar las distinciones entre las rutas que emplearon los españoles y los caminos locales, que al parecer no fueron utilizados por los europeos.

Dos trabajos de Chile, uno de Iván Muñoz sobre las especificaciones del Qhapaq Ñan en la precordillera de Arica, que apunta a reconocer al papel trascendente de la ruta inka para definir el poblamiento tardío, basado en una ruta preexistente, y otro de Cecilia Sanhueza, que profundiza en el tema de las probables significaciones de los hitos camineros de la región de Antofagasta, representan aportes al entendimiento del camino y sus relaciones con las poblaciones locales en el primer caso, y en cómo los inkas emplearon las saywas en la ordenación simbólica y efectiva de un amplio espacio del desierto de Atacama, en el segundo caso.

Roberto Bárcena propone que la quebrada del arroyo Peña Negra y el paso de La Ollita, constituyeron uno de los focos de mayor transitabilidad desde épocas prehispánicas, inkaicas, coloniales y posteriores. De igual forma, con su investigación desestima el planteamiento historiográfico clásico de la utilización del paso San Francisco por parte de Diego de Almagro y su hueste.

Cierra este número Sergio Martin, también con un artículo dedicado a un espacio riojano. Postula que las particulares evidencias arqueológicas inkas de la Sierra de Famatina, tales como algunas singularidades del camino, ushnus y plataformas ceremoniales, junto a otros sitios identificados, representan en conjunto manifestaciones ideológicas que caracterizan este territorio ubicado al sur del Collasuyu, como una wak'a interregional.

Estas contribuciones, siguiendo a las presentadas en el número anterior, destacan la vitalidad análitica, teórica e interpretativa de la temática vial inkaica, que ha logrado trascender las aproximaciones etnohistóricas que marcaron inicialmente la problemática en el siglo xx. Asimismo, van más allá de las indispensables aunque básicas descripciones del camino, implementando estudios macro y micromorfológicos, y una vision sistémica que integra los distintos componentes de una determinada ocupación inkaica, con una ineludible articulación simétrica con el paisaje, inquiriendo, igualmente, en las probables significaciones del sistema caminero inka.

De esta forma, las ponencias, las discusiones y las actas publicadas del Qhapaq Ñan I, Taller Internacional en torno al Sistema Vial Inkaico, han permitido configurar arqueológicamente un primer acercamiento colectivo hacia la relevancia económica, política, social y ceremonial del caminar en los Andes durante el Tawantinsuyu. Sin embargo, también han posibilitado comprender que las rutas y las vías de comunicación fueron consustanciales al desarrollo de las sociedades andinas y su memoria colectiva a lo largo del tiempo, cumpliendo, además, un rol trascendente en la actualidad. 